January 2000

\title{
Hepatitis C: knowledge, attitudes and practices among orthopedic trainee surgeons in Pakistan
}

J S. Rana

Aga Khan University

A R. Khan

Aga Khan University

A A. Haleem

Aga Khan University

F N. Khan

Aga Khan University

A Gul

Aga Khan University

See next page for additional authors

Follow this and additional works at: https://ecommons.aku.edu/

pakistan_fhs_mc_med_gastroenterol

Part of the Gastroenterology Commons

\section{Recommended Citation}

Rana, J. S., Khan, A. R., Haleem, A. A., Khan, F. N., Gul, A., Sarwari, A. R. (2000). Hepatitis C: knowledge, attitudes and practices among orthopedic trainee surgeons in Pakistan. Annals of Saudi Medicine, 20(2018-05-06), 477-479.

Available at: https://ecommons.aku.edu/pakistan_fhs_mc_med_gastroenterol/198 
Authors

J S. Rana, A R. Khan, A A. Haleem, F N. Khan, A Gul, and A R. Sarwari 


\title{
Hepatitis C: Knowledge, Attitudes and Practices among Orthopedic Trainee Surgeons in Pakistan
}

\author{
J.S. Rana, MD; A.R. Khan, MD; A.A. Haleem, MBBS; \\ F.N. Khan, MD; A. Gul, MD; A.R. Sarwari, MD
}

From the Departments of Medicine and Orthopedic Surgery, The Aga Khan University Hospital, Karachi, Pakistan.

Address reprint requests and correspondence to Dr. Sarwari: Department of Medicine, The Aga Khan University Hospital, Stadium Road, P.O. Box 3500, Karachi 74800, Pakistan.

Accepted for publication 20 October 2000. Received 23 November 1999.

JS Rana, AR Khan, AA Haleem, FN Khan, A Gul, AR Sarwari, Hepatitis C: Knowledge, Attitudes and Practices among Orthopedic Trainee Surgeons in Pakistan. 2000; 20(5-6): 477-479

Hepatitis $\mathrm{C}$ virus $(\mathrm{HCV})$, the major causative agent of non-A and non-B hepatitis, poses a serious worldwide health problem. An estimated 100 million individuals worldwide are chronically infected with HCV. High prevalence rates have been found in Southeast Asian countries, such as Thailand, Malaysia and India. ${ }^{1-3}$ Hepatitis C is the most common chronic blood-borne infection in the U.S. ${ }^{4}$ In Pakistan, the seroprevalence of HCV is $6.7 \%$ in women and $1.3 \%$ in children. Hepatitis C accounts for approximately $20 \%$ of cases of acute hepatitis, $70 \%$ of chronic hepatitis and $30 \%$ of end-stage liver disease in the U.S. ${ }^{6}$

The hepatitis $\mathrm{C}$ virus is a single-stranded RNA virus of the Flaviviridae family. Individual isolates consist of a closely related yet heterogeneous population of viral genomes (quasispecies). Probably as a consequence of this genetic diversity, HCV has the ability to escape the host's immune surveillance, leading to a high rate of chronic infection. The extensive genetic heterogeneity of HCV has important diagnostic and clinical implications, perhaps explaining the variation in clinical course, difficulties in vaccine development, and lack of response to therapy. ${ }^{7}$

$\mathrm{HCV}$ is generally transmitted by the parenteral route. It is also transmitted by needle-stick injuries, sexual contact, and vertically from mother to fetus. ${ }^{8}$ Hepatitis $\mathrm{C}$ exposure and antibody positivity rates among injection drug users have been reported to be higher than $50 \%$ compared to $10 \%$ in the same general population. ${ }^{9-12}$ Other known risk factors include ear piercing, acupuncture, tattoos, and cultural procedures involving blood contact. ${ }^{13-15}$ The use of inadequately sterilized undisposable medical materials, e.g., needles and scalpels, has also been shown to transmit HCV. ${ }^{16}$

There is some evidence of occupational and nosocomial transmission of HCV infection. Inadvertent needlestick injuries and lack of application of universal precautions may be contributing factors. ${ }^{15}$ About $80 \%$ of HCVpositive surgical operation room personnel in a hospital in Pakistan had more than four needle-stick injuries per year in five years. ${ }^{17}$ In one Pakistani community, HCV seroprevalence was $6.5 \%$, and individuals who received more therapeutic injections were found to be at a higher risk of infection. ${ }^{18}$

Data on the natural history of HCV is limited because the onset of infection is often unrecognized, and the early course of disease is indolent and protracted in most individuals. ${ }^{19}$ Approximately $60 \%-70 \%$ of HCV patients have no discernable symptoms, 20\%-30\% may have jaundice, and 10\%-20\% may have nonspecific symptoms (e.g., anorexia, malaise, or abdominal pain). About $75 \%-85 \%$ go on to develop chronic hepatitis. Research indicates that $10 \%-20 \%$ of chronically infected individuals are likely to develop cirrhosis over a period of 20-30 years, while 1\%$5 \%$ may go on to develop hepatocellular carcinoma. Reports from Pakistan show that 22\%-33\% of biopsy-proven cases of hepatocellular carcinoma had HCV infection. ${ }^{20,21}$

The volume of epidemiological data concerning hepatitis $\mathrm{C}$ is small compared with that concerning other infectious diseases such as AIDS and hepatitis B. The few knowledge, attitude and practice (KAP) studies concerning AIDS and hepatitis B have concluded that KAP concerning these diseases are severely deficient among health care professionals. Awareness is particularly crucial in the case of hepatitis $C$ as: 1) there is no vaccine currently available (unlike hepatitis B); ${ }^{22}$ and 2) infected persons serve as a source of transmission to others and are at a risk for chronic liver disease during the first two or three decades. ${ }^{4}$

Since surgical specialty residents have regular contact with HCV patients, they should be aware of the dangers of the condition and the necessary precautions that need to be taken. Our study targeted this group of health care personnel, as their knowledge, attitudes and practices are crucial in the management of HCV.

\section{Subjects and Methods}

Orthopedic trainee surgeons from three provinces and seven cities in Pakistan were surveyed. These residents 
are normally directly exposed to blood products and to incidents like needle pricks during the procedures they participate in. Our aim was to determine the knowledge, attitude and practices of these health professionals.

Data collection was carried out using a self-administered, close-ended structured questionnaire. The questionnaire was distributed to orthopedic surgery residents at the Annual Orthopedic Review Course in 1998 at the Aga Khan University Hospital, Karachi. Only participants who were part of an orthopedic residency program at the time were chosen. Respondents were given a 10-minute briefing on the aims of the study. One researcher was present during the survey administration to answer queries raised by respondents. The administration of the questionnaire lasted around half an hour.

All 43 residents except one were male. Their ages ranged from 26 to 43 years, with a median of 32.5 years. The year of graduation was between 1980 and 1997, with a median year of 1990. The average number of years spent in the orthopedic surgery program was four years.

\section{Results}

\section{Level of Hepatitis C Knowledge}

Only $16 \%$ of the surgical residents knew that there was a vaccine for hepatitis A. Though $84 \%$ knew that there was no vaccine for hepatitis C, the majority $(56 \%)$ were unaware that HCV was a sexually transmitted disease and $82 \%$ did not know about the possibility of it being transmitted perinatally. Of all the subjects, $93 \%$ knew that $\mathrm{HCV}$ could be transmitted through blood transfusion and $88 \%$ knew about its transmission through a needle-stick injury. As well, 65\% did not know that HCV is initially asymptomatic. Knowledge about the complications of HCV was adequate. Most of the residents were unaware of the physical properties of the virus, i.e., what destroys it, thus they incorrectly estimated the seroconversion rates with exposure to patients. This finding correlates with another study. ${ }^{23}$ Overall, there were significant gaps in the knowledge of the hepatitis $\mathrm{C}$ virus transmission.

\section{Practices Regarding Hepatitis C}

Seventy-four percent of subjects had been vaccinated for HBV. This is an encouraging finding and was found to be better than the vaccination prevalence of 59\% in a Western study. ${ }^{23}$ When handling a known case of HCV, $87 \%$ of subjects used an extra pair of gloves, while only $50 \%$ took extra care with needles. This particular finding is consistent with their poor knowledge of the higher risk of infectivity of HCV with needle pricks. Most subjects used two pairs of gloves except for minor surgeries. The median number of surgeries participated in was 12 in the previous month, 150 in the previous year and 300 in the previous three years. The median number of needle pricks was one in the previous month, three in the previous year and five in the previous three years. Only $16 \%$ of subjects knew the serostatus of the patients they were pricked from, and only a similar number checked their own serology after a needle-prick injury. The gravity of the situation is amplified by the fact that only $28 \%$ of the residents knew their own serostatus for HCV compared to $60 \%$ for HBV. Another significant finding was that $60 \%$ of the trainee surgeons were in habit of handling needles with their bare hands.

\section{Attitudes}

With regards to attitudes towards $\mathrm{HCV}, 42 \%$ of the respondents said they would tell their patients about their own HCV seropositivity and 64\% of residents did not believe in interferon therapy. Of all the respondents, $40 \%$ were in a habit of reading medical literature at least once a week.

\section{Discussion}

The emergence of $\mathrm{HCV}$ as an important blood-borne pathogen compels us to focus our attention on protecting health care workers from illness, disability or death. ${ }^{24}$ For surgeons, the prevalence of infection with HCV increases with increasing age. ${ }^{25,26}$ Awareness of the dangers of this infectious disease should be instilled at an early stage of a surgeon's training.

According to Johanet et al., out of 3554 operative procedures (visceral, orthopedic and vascular), $4 \%$ of procedures were associated with percutaneous exposure of blood, and surgeons were involved in $51 \%$ of cases of percutaneous exposure. ${ }^{27} \mathrm{HCV}$ and HBV are more important than HIV as a cause of morbidity and death of surgeons. ${ }^{28}$ The policy of standard precautions is not observed in all hospital operation theaters. The need to implement standard precautions is reinforced by the fact that despite the knowledge of how to handle hepatitis C patients, $49 \%$ of the respondents in one study could not avoid handling of blood. Similarly, handling needles with bare hands shows a need for physician education in standard precautions against blood-borne diseases. 
The fact that only $16 \%$ of the subjects were in the habit of checking their own serology after a needle-prick injury shows a lack of screening of both patient and victim, which should be a part of a hospital-wide protocol to be followed after occupational exposure to blood and body fluids. The recommended protocol to be implemented is to get baseline testing for anti-HCV for the source. For the person exposed to an HCV-positive source, recommendations include baseline testing for anti-HCV and ALT activity, with follow-up tests for both at four to six months. Confirmation by supplemental anti-HCV testing of all positive enzyme immunoassay results should be done. $^{4}$

In the light of the above results, changing the attitude of health care workers towards HCV becomes increasingly important. We suggest that all new surgical residents who are at risk of exposure to blood should be given a pre-test, a lecture, a demonstration of standard precautions and infection control procedures, followed by a post-test. This approach has proven to be effective and is recommended. ${ }^{29}$ McCarthy et al. have emphasized that orthopedic trauma surgeons need to improve their compliance with infection control recommendations. ${ }^{30}$ Further efforts by the individuals and their institutions are warranted.

The risk of nosocomial transmission of HIV, HBV and other blood-borne pathogens can be minimized if healthcare workers adopt the following general guidelines: ${ }^{4,31}$

- Take care to prevent injuries when using needles, scalpels, and other sharp instruments or devices, when handling sharp instruments after procedures, when cleaning used instruments, and when disposing of used needles.

- Do not recap used needles by hand; do not remove used needles from disposable syringes by hand, and do not bend, break, or otherwise manipulate used needles by hand. Place used disposable syringes and needles, scalpel blades, and other sharp items in puncture-resistant containers for disposal.

- Use protective barriers to prevent exposure to blood, body fluids containing visible blood and other fluids to which universal precautions apply. The type of protective barrier(s) should be appropriate for the procedure being performed and the type of exposure anticipated.

- Immediately and thoroughly wash hands and other skin surfaces that are contaminated with blood, body fluids containing visible blood, or other body fluids to which universal precautions apply.

- Use gloves for performing all phlebotomy procedures.

\section{References}

1. Suwanagool S, Tieangrim S, Ratasanuwan W, et al. Seroprevalence of anti-HCV-infected persons and general population. J Med Assoc Thailand 1995;76:611-7.

2. Irshad M, Archarya SK, Joshi YK. Prevalence of hepatitis C virus antibodies in the general population and in selected groups of patients in Delhi. Indian J Med Res 1995;102:162-4.

3. Duraisamy G, Zuridah H, Ariffin MY. Prevalence of hepatitis C virus antibodies in blood donors in Malaysia. Med J Malaysia 1993:48:313-6.

4. Morbidity and Mortality Weekly Report. Recommendations for prevention and control of hepatitis C virus (HCV) and infection and HCV-related chronic disease. MMWR 1998;47:No. RR-19.

5. Parker SP, Khan HI, Cubitt WD. Detection of antibodies to hepatitis C in dried blood spot samples from mothers and their offspring in Lahore, Pakistan. J Clin Microbiol 1999;37:2061-3.

6. Alter MJ, Mast EE. The epidemiology of viral hepatitis in the United States. Gastroenterol Clin North Am 1994;23:435-437.

7. National Institutes of Health Consensus Development Conference Panel Statement. Management of Hepatitis C. Hepatology 1997; 26(Suppl 1):2S-10S.

8. Alter MJ, Hadler SC, Judson FN, Mares A, Alexander J, Hu PY, et al. Risk factors for acute non-A, non-B hepatitis and association with hepatitis C virus infection. JAMA 1990;264:2231-5.

9. Fingerhood MI, Jasinski DR, Sullivans JT. Prevalence of hepatitis C in a chemically dependent population. Arch Intern Med 1993;153:2025-30.

10. Mayyaon S, Shuofman EN, Engelhard D, Shouval D. Exposure to hepatitis B and C and HTLV-1 and HTLV-2 among Israeli drug abusers in Jerusalem. Addiction 1994;89:869-74.

11. Van Ameijiden EJ, van den Hock JA, Mientjes GH, Cantino RA. A longitudinal study on the incidence and transmission patterns of HIV, HBV and HCV infection among drug users in Amsterdam. Eur J Epidemiol 1993;9:255-62.

12. Woodfield DG, Harness M, Rix-Trott K. Hepatitis C virus infections in oral and injectable drug users. N Z Med J 
1993;106:322-34.

13. Kiyosawa K, Tanaka E, Sodeyama T, et al. Transmission of hepatitis C in an isolated area in Japan. Community-acquired infection. Gastro-enterology 1994;106:1596-602.

14. Mele A, Corona R, Tosti ME, et al. Beauty treatments and risk of parenterally transmitted hepatitis: results from the hepatitis surveillance system in Italy. Scand J Infect Dis 1995;27:441-4.

15. Conry-Cantilena C, Van Raden M, Gibble J, Melpolder J, Shakil AO, Viladomiu L, et al. Routes of infection, viremia and liver disease in blood donors found to have hepatitis C infection. N Engl J Med 1996;334:1691-6.

16. Hayashi J, Kishihara Y, Yamaji K, Yoshimura E, Kawakami Y, Akazawa K, et al Transmission of HCV by health care workers in a rural area of Japan. Am J Gastroenterol 1995;9:794-9.

17. Mujeeb SA, Khatri Y, Khanani R. Frequency of parenteral exposure and seroprevalence of HBV, HCV, and HIV among operation room personnel. J Hosp Infect 1998;38:133-7.

18. Luby SP, Qamruddin K, Shah AA, Omair A, Pasha O, Khan AJ, et al. The relationship between therapeutic injections and high prevalence of hepatitis C infection in Hafizabad, Pakistan. Epidemiol Infect 1997;119:349-56.

19. Seeff LB. Natural history of hepatitis C. Hepatology 1997;26(Suppl 1):21S-28S.

20. Tong CY, Khan R, Beeching NJ, Tariq WU, Hart CA, Ahmad N, et al. The occurrence of hepatitis B and C viruses in Pakistani patients with chronic liver disease and hepatocellular carcinoma. Epidemiol Infect 1996;117:327-32.

21. Abdul-Majeed S, Jamal Q, Khanani R, Iqbal N, Kaher S. Prevalence of hepatitis B surface antigen and HCV antibodies in hepatocellular carcinoma cases in Karachi, Pakistan. Trop Doct 1997;27:45-6.

22. Crawford JM. The liver and the biliary tract. In: Kumar V, Cotran RS, Robbins SL, editors. Basic pathology. 6th edition. Philadelphia: WB Saunders, 1997:516-55.

23. Patterson JM, Novack CB, Mackinon SE, et al. Surgeon's concern and practices of protection against blood-borne pathogens. Ann Surg 1998;228:266-72.

24. Davis MS. Occupational hazards of operating: opportunities for improvement. Infect Control Hosp Epidemiol 1996;17:691-3.

25. Shapiro CN, Tokars JI, Chamberland ME. Use of HBV vaccine and infection with HBV and HBC among orthopedic surgeons. The American Academy of Orthopedic Surgeons. Serosurvey Study Committee. J Bone Joint Surg Am 1996;78:1791802.

26. Thomas DL, Gruninga SE, Siew C. et al. Occupational risk of HCV infection among general dentists and oral surgeons in North America. Am J Med 1996;100:41-5.

27. Johanet H, Antona D, Bouvet E. Risks of accidental exposure to blood in the operating room: results of a multicenter prospective study. Ann Chir 1995;49:403-10.

28. Fry DE. Occupational risk of infection in the surgical trauma patients. Am J Surg 1993;165(Suppl 2A):26S-33S.

29. Calabro K, Weltge A, Parnell S, et al. Intervention for medical students: effective infection control. Am J Infect Control 1998;26: 431-6.

30. McCarthy ML, Bosse MJ, Preas MA, De-Long WG, Gunther SF, Moed BR. Orthopedic trauma surgeons' attitudes and practices towards blood-borne pathogens. J Orthop Trauma 1996;10:383-8.

31. Centers of Disease Control. Perspective in disease prevention and health promotion update. Universal precautions for prevention of transmission of HIV, HBV, and other bloodborne pathogens in health care settings. MMWR 1988;37:24. 